\title{
Late-onset central hypoventilation syndrome: a family genetic study
}

\author{
L.S. Doherty*, J.L. Kiely*, P.C. Deegan*, G. Nolan*, S. McCabe" , A.J. Green ${ }^{\#, ~, ~}$ \\ S. Ennis ${ }^{\#, \uparrow}$ and W.T. McNicholas ${ }^{\star * \#}$
}

ABSTRACT: Congenital central hypoventilation syndrome is a rare disorder characterised by chronic alveolar hypoventilation, which becomes more pronounced during sleep and may be associated with neurocristopathies, such as Hirchsprung's disease. A mutation in the PHOX2B gene has recently been identified.

In a family of both parents and five offspring, detailed clinical assessment, pulmonary function testing, overnight sleep studies and ventilatory responsiveness to progressive hypercapnia $\left(V^{\prime} \mathrm{R}, \mathrm{CO}_{2}\right)$ were performed, in addition to analysis of known genetic loci for this condition.

The father and four of the offspring demonstrated features of central hypoventilation with nonapnoeic oxygen desaturation during sleep and diminished $V^{\prime} \mathrm{R}, \mathrm{CO}_{2}$, despite normal pulmonary function. The lowest sleep saturation was median (range) $79 \%$ (67-83\%) and $V^{\prime} R, \mathrm{CO}_{2}$ was 2.1 (0.03-4.3) $\mathrm{L} \cdot \mathrm{min}^{-1} \cdot \mathrm{kPa}^{-1}$. The normal values for the authors' centre (St Vincent's University Hospital, Dublin, Ireland) are $15-40 \mathrm{~L} \cdot \mathrm{min}^{-1} \cdot \mathrm{kPa}^{-1}$. An in-frame five amino acid polyalanine expansion of the PHOX2B gene was found in all affected subjects, while the mother and fifth child, who did not have features of central hypoventilation, had a normal PHOX2B gene. Magnetic resonance imaging of the brainstem in one severely affected child was normal.

The present study of a unique family confirms that transmission of late-onset congenital central hypoventilation syndrome is autosomal dominant in nature.

KEYWORDS: Central hypoventilation, congenital, Ondine's curse, sleep, PHOX2B gene

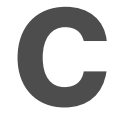
ongenital central hypoventilation syndrome (CCHS), also referred to as Ondine's curse, is a rare condition characterised by ventilatory impairment that results in arterial hypoxaemia, which is worsened by sleep and occurs in patients with normal mechanical properties of the lung. It is diagnosed in the absence of primary neuromuscular, pulmonary or cardiac disease, or an identifiable brainstem lesion [1]. The syndrome is usually idiopathic but may occur in association with Hirschprung's disease and disorders of neural crest origin. Studies in monozygotic twins, female siblings, male and female half-siblings, and mother-child transmission support a genetic aetiology [2-6]. More recently, an autosomal dominant mode of inheritance has been proposed following the finding of high-frequency (91-97\%) heterozygous expansion mutations in a polyalanine tract within exon 3 of $P H O X 2 B$ gene $[7,8]$. Although patients typically present in the newborn period and rarely in later infancy, there have been reports of patients presenting with CCHS in adulthood [9-16]. Initially, it was thought that $P H O X 2 B$ mutations occurred de novo
$[17,18]$. However, WEESE-MAYER et al. [16] recently described a father and daughter with late-onset CCHS (LOCHS) and the same PHOX2B mutation, indicating autosomal dominant inheritance [16]. The present study reports the first complete family in which one parent and four out of five offspring demonstrated features of LOCHS, with genetic analysis confirming the presence of the same PHOX2B expansion mutation.

\section{METHODS}

Following identification of central hypoventilation in two siblings, a detailed evaluation was performed of the complete family, consisting of both parents and five offspring. In addition to a full clinical assessment, overnight supervised polysomnography was performed in a sleep laboratory in both parents and the three oldest children using standard techniques [19]; home overnight oximetry was performed in the two youngest children. Pulmonary function testing, including spirometry, diffusing capacity and testing of respiratory muscle strength, was performed using a proprietary system (Jaeger, Wurzburg, Germany) and arterial blood gas
AFFILIATIONS

${ }^{\star}$ Respiratory Sleep Disorders Unit, St.Vincent's University Hospital, ${ }^{\#}$ Conway Institute of Biomolecular and Biomedical Research, University College Dublin, and

- National Centre for Medical Genetics, Our Lady's Hospital for Sick Children, Dublin, Ireland.

CORRESPONDENCE

W.T. McNicholas

Dept of Respiratory Medicine

St. Vincent's University Hospital Elm Park

Dublin 4

Ireland

Fax: 35312697949

E-mail: walter.mcnicholas@ucd.ie

Received:

January 052006

Accepted after revision:

September 212006

SUPPORT STATEMENT

This paper was not funded.

STATEMENT OF INTEREST

None declared. 
TABLE 1 Pulmonary function and sleep data of the index case's family

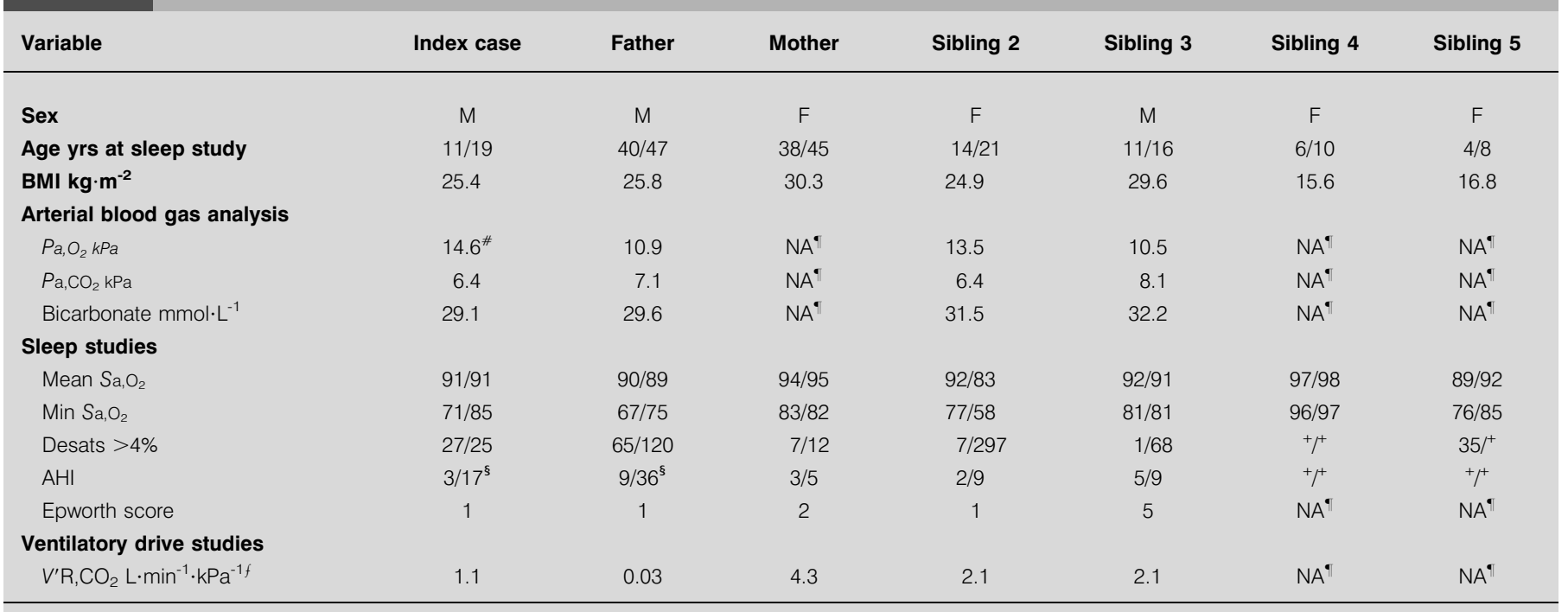

Data are presented as that obtained from the initial/follow-up sleep studies, unless otherwise stated. M: male; $\mathrm{F}$ : female; $\mathrm{BMI}$ : body mass index; $\mathrm{Pa}, \mathrm{O}_{2}$ : arterial oxygen tension; $\mathrm{Pa}_{2} \mathrm{CO}_{2}$ : arterial carbon dioxide tension; $\mathrm{Sa}_{1} \mathrm{O}_{2}$ : arterial oxygen saturation; Desats $>4 \%$ : number of desaturations $>4 \%$ during the overnight sleep study; $\mathrm{AHI}$ : apnoea/hypopnoea index; NA: not available; $V^{\prime} \mathrm{R}, \mathrm{CO}_{2}$, ventilatory response to progressive hypercapnia. ${ }^{*}$ : arterial blood gas analysis performed while on oxygen therapy at $2 \mathrm{~L} \cdot$ breaths $\cdot \mathrm{min}^{-1} ;{ }^{\bullet}$ : data unavailable because of refusal (mother) or could not be performed (child 4 and 5 ); ${ }^{+}$: sleep studies were repeated in the two younger family members after a shorter interval; ${ }^{\S}$ : apnoeic and hypopnoeic events were predominantly $(>80 \%)$ obstructive in nature; ${ }^{f}$ : normal range for the current authors' centre (St Vincent's University Hospital, Dublin, Ireland) is 5-40.

analysis was performed by radial/femoral arterial puncture. Ventilatory responsiveness to progressive hypercapnia $\left(V^{\prime} \mathrm{R}, \mathrm{CO}_{2}\right)$ was measured using the Read rebreathing technique in all but the two youngest children [20]. Briefly, subjects rebreathed into an airtight 5-L bag containing a mixture of 7\% carbon dioxide and $93 \%$ oxygen. The spirometer technology used to monitor ventilation was based on a bi-directional rotating vane principle (flow sensing), which was calibrated by a 3-L syringe prior to testing. A continuous record of $\mathrm{CO}_{2}$ concentration in the expired gas was obtained by a $\mathrm{CO}_{2}$ analyser within the circuit. At commencement of the test, subjects took three deep breaths to ensure rapid equilibration between the rebreathing bag, mixed venous $\mathrm{CO}_{2}$ tension $\left(\mathrm{PCO}_{2}\right)$ and gas in the lung. Rebreathing continued for 4-6 min or until onset of subject discomfort. Discarding the plateau phase of the graph, ventilatory hypercapnic drive was calculated from the slope produced by change in ventilation $\left(\mathrm{L} \cdot \mathrm{min}^{-1}\right)$ and change in end-tidal $\mathrm{PCO}_{2}$.

Genetic studies were performed on venous blood samples to identify a genetic basis for hypoventilation. Linkage studies were performed using polymorphic anonymous markers, closely linked to a series of genes known to be associated with neurocristopathies, and PCR amplification by denaturing high-power liquid chromatography in addition to direct sequencing of PCR product.

\section{RESULTS}

\section{Clinical details}

Index cases

An 11-yr-old male presented with recurring episodes of hypercapnic respiratory failure. In the previous 5 yrs he had three episodes of pneumonia complicated by hypercapnic respiratory failure, requiring mechanical ventilation on one occasion. He had no clinical features of neuromuscular, cardiac or respiratory disease, or an underlying hypothalamic/endocrine disorder. Overnight polysomnography showed persistent nonapnoeic oxygen desaturation not unusual to rapid eye movement (REM) sleep and occurring with equal frequency in non-REM sleep. Although overnight capnometry was not performed, daytime arterial blood gas analysis showed hypoxaemia and hypercapnia, consistent with a central hypoventilation disorder (table 1) [19]. No pathological arrhythmia or evidence of sinus arrest was identified on overnight ECG tracing in any family member. The echocardiograph of the index case was reported as showing a dilated right heart, mild tricuspid regurgitation and an estimated pulmonary artery systolic pressure of $38 \mathrm{mmHg}$. Chest radiography, pulmonary function testing and magnetic resonance scanning of the brain were normal. LOCHS was diagnosed and the patient was later started on domiciliary nocturnal noninvasive ventilation (NIV).

Two years later, the older sister of the index case, then aged 14 yrs, presented with a similar history of recurrent respiratory tract infections complicated by severe hypercapnia requiring invasive ventilatory support. Similar investigations were undertaken, which were in keeping with central hypoventilation (table 1, sibling 2), and she was also started on domiciliary nocturnal NIV.

Family details

The cases of the two siblings prompted the current authors to screen the remaining family for LOCHS, which consisted of the 


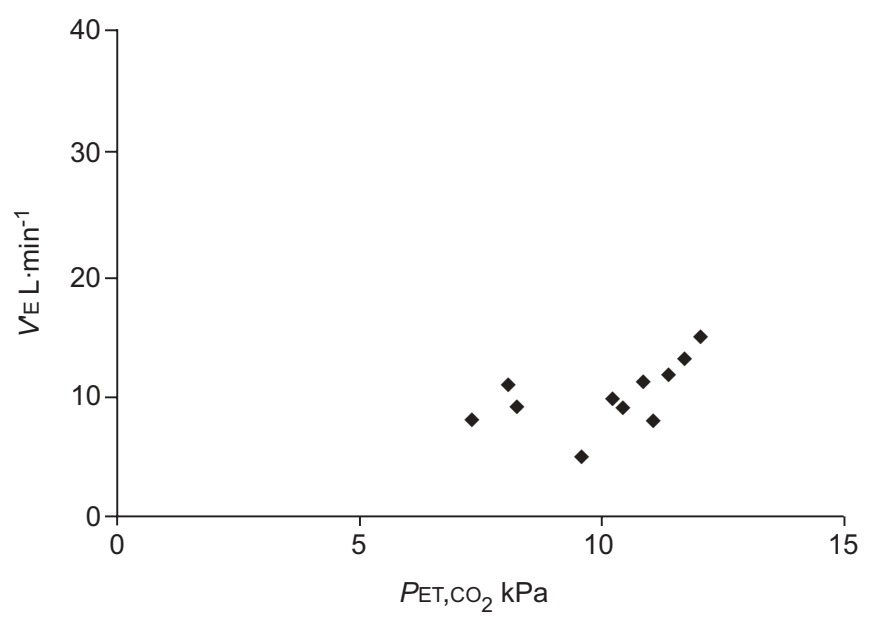

FIGURE 1. Ventilatory response to progressive hypercapnia in the index case performed by the rebreathing technique. $V^{\prime} \mathrm{E}$ : minute ventilation; $P \mathrm{ET}, \mathrm{CO}_{2}$ : end-tidal carbon dioxide tension.

parents (aged 41 and $39 \mathrm{yrs}$ ), a son (aged $11 \mathrm{yrs}$ ) and two daughters (aged 6 and 4 yrs). All were asymptomatic, had no clinical features of autonomic nervous system dysfunction, no past medical history and had normal pulmonary function tests. Arterial blood gas analysis and overnight sleep studies revealed evidence of nocturnal hypoventilation in the father and four out of the five children (excluding the second youngest) to varying degrees of severity (table 1). $V^{\prime} \mathrm{RCO}_{2}$ was reduced in the father and three eldest siblings, and showed borderline values in the mother (table 1; fig. 1) [20]. In the mother, two overnight polysomnogram studies demonstrated occasional transient, episodic oxygen desaturation into the mid $80 \%$ range without associated central or obstructive apnoea (table 1), but the mother did not consent to arterial blood gas analysis. An enquiry regarding the extended family did not identify any other member with a history suggestive of this disorder.

Follow-up sleep studies after an average of 5 yrs showed deterioration in several family members (table 1). On repeat sleep studies, both the index case and father had an elevated apnoea/hypopnoea index of 17 and 36 episodes $\cdot \mathrm{h}^{-1}$, respectively. However, neither had symptoms of an obstructive sleep apnoea syndrome, such as snoring or excessive daytime sleepiness, and both had an Epworth sleepiness score of one out of a maximum 24 [21]. Indeed, in this family, quality of life scores, as measured by short form-36, Hospital Anxiety and Depression scores and Epworth scores, did not deviate from normal subjects once matched for age and sex [21-23].

\section{Genetic findings}

Linkage studies of genes associated with neurocristopathies, namely RET, GDNF, EDN3, EDNRB, BDNF, SOX10, ECE1 and NTN, showed no evidence of association with the disease. An associated gene, hASH1, was also excluded by linkage. In addition, no mutations were found in the hASH1, RET or GDNRF genes using PCR amplification of all exons and direct sequencing of PCR products. However, on amplification and sequencing of the $P H O X 2 B$ gene, the father and four affected children all demonstrated a 15 base pair insertion at nucleotide a)

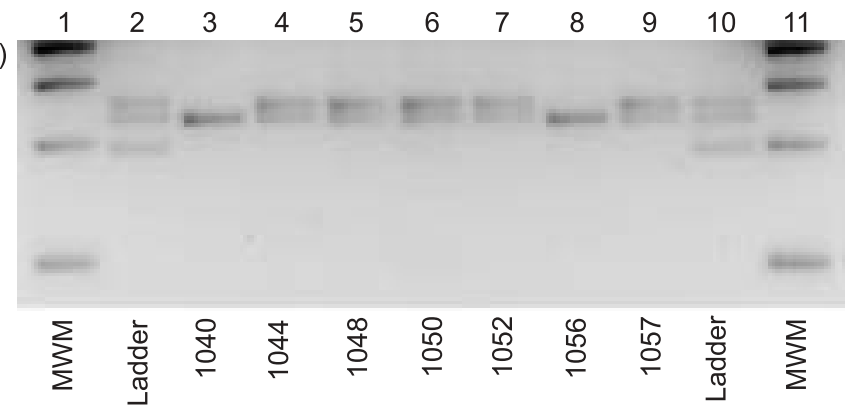

b) CAGCGGCGGCGGCCGCGGCAGCGGCGGCGGCCCCACCGGCGGCGGCGGCAGCGGCAGCG

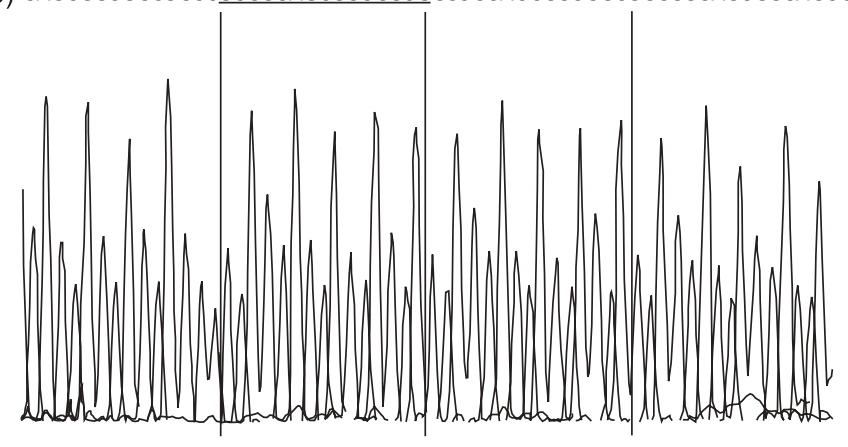

FIGURE 2. a) Polyalanine expansion mutations of the $P H O X 2 B$ gene in a family with late-onset congenital central hypoventilation syndrome (LOCHS). PCR products of the polyalanine tract (exon 3 ) from a LOCHS family were analysed by gel electrophoresis on $4 \%$ (weight/volume) TBE agarose gels, stained with $0.6 \mathrm{mg} \cdot \mathrm{mL}^{-1}$ ethidium bromide and visualised under ultraviolet light. Lanes 1 and 11: molecular weight marker; lanes 2 and 10: allelic ladder (10/20/25), containing alleles 10Ala (-30 base pairs), normal 20Ala and $+5 \mathrm{Ala}$ ( +15 base pairs); lane 3 : mother (20/20), unaffected; lane 4; father (20/25), affected; lane 5: daughter (20/ 25), affected; lane 6: son (20/25), affected; lane 7: son (20/25), affected; lane 8: daughter (20/20), unaffected; lane 9: daughter (20/25), affected. b) Sequence electropherogram of the +5 polyalanine tract (exon 3 ) expansion allele indicating the 15 base pair insertion.

721 of the $P H O X 2 B$ gene (fig. 2). This in-frame insertion is predicted to give a five amino acid polyalanine expansion previously seen in CCHS, and reported only recently in a delayed onset case of CCHS [16]. The mother and unaffected child had a normal $P H O X 2 B$ gene analysis.

\section{DISCUSSION}

The present study reports a unique occurrence of a central hypoventilation disorder in most members of a family, which is associated with a known genetic mutation and is in keeping with a diagnosis of LOCHS. However, none of the family members complained of any symptoms of nocturnal hypoventilation or demonstrated any of the neurological, cardiac or ophthalmological features frequently seen in children with CCHS. Had it not been for the screening by the current authors, it is likely the family would have remained undiagnosed [24]; however, the current authors recognise that the condition may have been present, but undetected, for many years previously. LOCHS is considered by some as synonymous with a distinct clinical entity of late-onset (childhood) CCHS, in association with hypothalamic dysfunction [25]. There are other case reports of adult-onset CCHS in the literature, but the small numbers may reflect the difficulty in 
recognising a condition that, as in this family, lacks symptoms [9-16]. Long-term prognosis remains unclear but the presence of cor pulmonale in two siblings and the interval deterioration sleep-related breathing disturbances are of concern (table 1).

Nocturnal hypoventilation could not be confirmed with overnight capnometry. However, with daytime arterial blood gas analysis in keeping with hypoventilation, normal chest radiographs and lung function tests, and nocturnal hypoxaemia without central or significant obstructive apnoeic episodes on the polysomnogram, the likelihood of an alternative diagnosis is low. Of concern is the elevated body mass index (BMI) in two of the affected siblings (sibling 3 at presentation and sibling 2, whose BMI was $35 \mathrm{~kg} \cdot \mathrm{m}^{-2}$ on follow up), since obesity can aggravate nocturnal hypoventilation by obesity displacement of the diaphragm in the supine position. The borderline $V^{\prime} \mathrm{R}, \mathrm{CO}_{2}$ values and mild oxygen desaturation in the mother raises the possibility of central hypoventilation, but far less than in the family members showing the PHOX2B mutation. However, the mother's high BMI also raises the possibility of obesity-related hypoventilation, which is also recognised to result in a low ventilatory drive pattern. [26].

The $P H O X 2 B$ gene located at chromosome $4 \mathrm{p} 12$ encodes a highly conserved homeobox domain transcription factor and was proposed as the disease-defining gene for CCHS by AMIEL et al. [17]. $P H O X 2 B$ is a transcriptional activator required for neurogenesis and pan-neuronal differentiation, including typespecific differentiation into the carotid body, the petrosal chemoreceptors that innervate it and the solitary tract nucleus onto which they project [27]. Mutations of this gene lead to a variety of disturbances of autonomic function, including CCHS and tumours of the sympathetic nervous system [28].

How LOCHS differs genetically from the usual early presentation of CCHS is unclear and may simply reflect a separate polymorphism or a hitherto unknown gene regulating the activity or expression of $P H O X 2 B$. $P H O X 2 B$ polyalanine repeat expansion mutation length also correlates with clinical features of autonomic nervous system dysfunction in CCHS patients [8]. To date, only 14 patients have been reported who have LOCHS and were tested for the PHOX2B mutation $[7,16,28$, 29]. Among them, 10 patients carried a $P H O X 2 B$ mutation with +5 alanine expansion, which is similar to the family members carrying a $P H O X 2 B$ mutation in the present study.

The present findings confirm that the small alanine expansion $(+5)$ is present in late-onset congenital central hypoventilation syndrome patients, compared with the longer expansion reported in patients with congenital central hypoventilation syndrome or congenital central hypoventilation syndrome plus Hirschsprung's disease. The current study represents the only complete family study of this mutation and the findings indicate an autosomal dominant mode of inheritance.

\section{ACKNOWLEDGEMENTS}

The authors are grateful to D. Gill (Temple Street Children's Hospital, Dublin, Ireland) for referring the index case and child 2. The authors are also grateful to the staff of the Pulmonary Function and Sleep Laboratories (St. Vincent's University
Hospital, Dublin) for performing pulmonary function and sleep studies.

\section{REFERENCES}

1 Idiopathic congenital central hypoventilation syndrome: diagnosis and management. American Thoracic Society. Am J Respir Crit Care Med 1999; 160: 368-373.

2 Khalifa MM, Flavin MA, Wherrett BA. Congenital central hypoventilation syndrome in monozygotic twins. J Pediatr 1988; 113: 853-855.

3 Haddad GG, Mazza NM, Defendini R, et al. Congenital failure of automatic control of ventilation, gastrointestinal motility and heart rate. Medicine (Baltimore) 1978; 57: 517-526.

4 Hamilton J, Bodurtha JN. Congenital central hypoventilation syndrome and Hirschsprung's disease in half sibs. $J$ Med Genet 1989; 26: 272-274.

5 Sritippayawan S, Hamutcu R, Kun SS, et al. Motherdaughter transmission of congenital central hypoventilation syndrome. Am J Respir Crit Care Med 2002; 166: 367-369.

6 Weese-Mayer DE, Berry-Kravis EM. Genetics of congenital central hypoventilation syndrome: lessons from a seemingly orphan disease. Am J Respir Crit Care Med 2004; 170: 16-21.

7 Trang H, Dehan M, Beaufils F, et al. The French Congenital Central Hypoventilation Syndrome Registry: general data, phenotype, and genotype. Chest 2005; 127: 72-79.

8 Weese-Mayer DE, Berry-Kravis EM, Zhou L, et al. Idiopathic congenital central hypoventilation syndrome: analysis of genes pertinent to early autonomic nervous system embryologic development and identification of mutations in PHOX2B. Am J Med Genet A 2003; 123: 267278.

9 McNicholas WT, Carter JL, Rutherford R, et al. Beneficial effect of oxygen in primary alveolar hypoventilation with central sleep apnea. Am Rev Respir Dis 1982; 125: 773-775.

10 Schlegel J, Kienast K, Fischer B, et al. Clinical late manifestation of Ondine's curse with pronounced primary, especially sleep related, alveolar hypoventilation. Pneumonologie 1995; 49: Suppl. 1, 55-57.

11 Bullemer F, Heindl S, Karg O. ["Ondine's curse" in adults]. Pneumologie 1999; 53: Suppl. 2, S91-S92.

12 Funada Y, Nishimura Y, Kamemura K, et al. Familial adult onset primary alveolar hypoventilation syndrome. Intern Med 2001; 40: 463-464.

13 Windisch W, Hennings E, Storre JH, et al. Long-term survival of a patient with congenital central hypoventilation syndrome despite the lack of continuous ventilatory support. Respiration 2004; 71: 195-198.

14 Roncoroni AJ, Montiel GC, Semeniuk GB. Bilateral carotid body paraganglioma and central alveolar hypoventilation. Respiration 2004; 71: 195-198.

15 Guilleminault C, Stoohs R, Schneider $\mathrm{H}$, et al. Central alveolar hypoventilation and sleep. Treatment by intermittent positive-pressure ventilation through nasal mask in an adult. Chest 1989; 96: 1210-1212.

16 Weese-Mayer DE, Berry-Kravis EM, Zhou L. Adult identified with congenital central hypoventilation 
syndrome: mutation in $\mathrm{PHOX} 2 \mathrm{~B}$ gene and late-onset CHS. Am J Respir Crit Care Med 2005; 171: 88.

17 Amiel J, Laudier B, Attie-Bitach T, et al. Polyalanine expansion and frameshift mutations of the paired-like homeobox gene PHOX2B in congenital central hypoventilation syndrome. Nat Genet 2003; 33: 459-461.

18 Sasaki A, Kanai M, Kijima K, et al. Molecular analysis of congenital central hypoventilation syndrome. Hum Genet 2003; 114: 22-26.

19 Practice parameters for the indications for polysomnography and related procedures. Polysomnography Task Force, American Sleep Disorders Association Standards of Practice Committee. Sleep 1997; 20: 406-422.

20 Read DJC. A clinical method for assessing the ventilatory response to carbon dioxide. Aust Ann Med 1967; 16: 20-32.

21 Johns MW. A new method for measuring daytime sleepiness: the Epworth sleepiness scale. Sleep 1991; 14: 540-545.

22 Zigmond AS, Snaith RP. The Hospital Anxiety and Depression Scale. Acta Psychiatrica Scandinavica 1983; 67: 361-370.

23 Ware JE. SF-36 Health Survey Manual and Interpretation Guide. Boston, Nimrod Press, 1993.
24 Weese-Mayer DE, Silvestri JM, Menzies LJ, et al. Congenital central hypoventilation syndrome: diagnosis, management, and long-term outcome in thirty-two children. J Pediatr 1992; 120: 381-387.

25 Katz ES, McGrath S, Marcus CL. Late-onset central hypoventilation with hypothalamic dysfunction: a distinct clinical syndrome. Pediatr Pulmonol 2000; 29: 62-68.

26 Zwillich CW, Sutton FD, Pierson DJ, Greagh EM, Weil JV. Decreased hypoxic ventilatory drive in the obesityhypoventilation syndrome. Am J Med 1975; 59: 343-348.

27 Dauger S, Pattyn A, Lofaso F, et al. Phox $2 b$ controls the development of peripheral chemoreceptors and afferent visceral pathways. Development 2003; 130: 6635-6642.

28 Trochet D, O’Brien LM, Gozal D, et al. PHOX2B genotype allows for prediction of tumor risk in congenital central hypoventilation syndrome. Am J Hum Genet 2005; 76: 421-426.

29 Matera I, Bachetti T, Puppo F, et al. PHOX2B mutations and polyalanine expansions correlate with the severity of the respiratory phenotype and associated symptoms in both congenital and late onset central hypoventilation syndrome. J Med Genet 2004; 41: 373-380. 